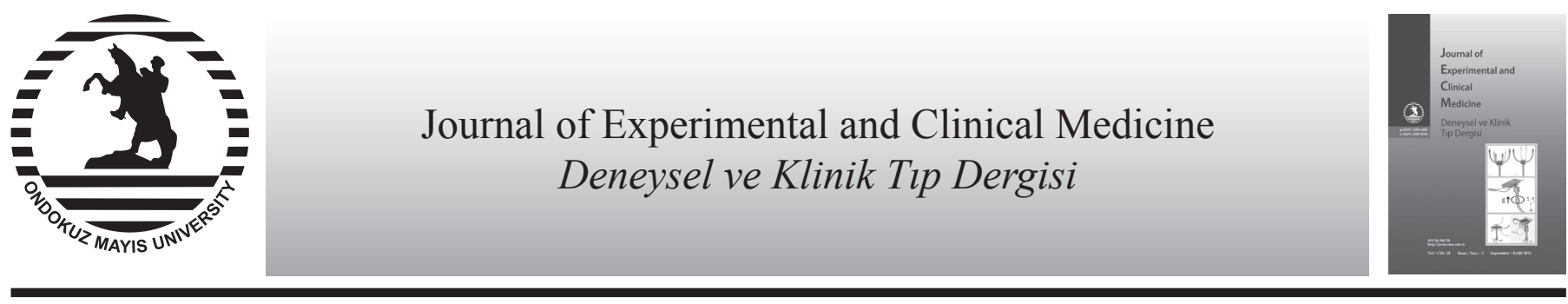

Case Report

doi: $10.5835 /$ jecm.omu.28.03.009

\title{
Spontaneous resolution of a herniated fragment cervical disc
}

\author{
Mesut Mete*, Mehmet Savran, Füsun Demirçivi Özer, Yusuf Kurtuluş Duransoy \\ Department of Neurosurgery, State Hospital, Nevsehir, Turkey
}

\begin{tabular}{|c|c|}
\hline ARTICLE INFO & ABSTRACT \\
\hline Article History & Although the spontaneous resolution of herniated nucleus pulposus is a well known phe- \\
\hline 05 / 07 / 2011 & nomenon in lumbar disc herniations, it is rarely encountered in the cervical region. The \\
\hline 29 / $07 / 2011$ & spontaneous resolution of a herniated cervical disc in a woman is reported to describe a \\
\hline \multirow{6}{*}{$\begin{array}{l}\text { * Correspondence to } \\
\text { Mesut Mete } \\
\text { Ragip Uner Mahallesi } \\
102 \text { sokak 24/6 } \\
\text { Nevsehir - TURKEY } \\
\text { e-mail: dr.mmete@hotmail.com }\end{array}$} & to discuss its mechanism. A woman with a large and fragment herniated cervical disc \\
\hline & refused to undergo operation and was followed-up for 1,5 months. In control magnetic \\
\hline & resonance imaging of the cervical spine revealed a complete regression of the herni- \\
\hline & ated disc material. Her symtoms were also alleviated. In large and fragment cervical disc \\
\hline & $\begin{array}{l}\text { herniations without severe myelopathy symptoms, potential for spontaneous regression } \\
\text { should be considered. }\end{array}$ \\
\hline & J. Exp. Clin. Med., 2011; 28:124-126 \\
\hline
\end{tabular}

\section{Keywords:}

Cervical vertebrae

Intervertebral disk displacement

Spontaneous disc resolution

Spinal cord disease

Hernia nucleus pulposus

Servical myelopathy

(C) 2011 OMU All rights reserved

\section{Introduction}

Since Guinto et al., reported a case of spontaneous regression of a herniated lumbar disc in 1984 (Guinto et al.,1984), this phenomenon in lumbar discs has been well documented and discussed (Keskil et al., 2004; Komori et al.,1998 ). However, there have been fewer reports of spontaneous regression of cervical disc herniation (CDH) (Krieger and Maniker, 1992; Song et al., 1999), especially ones confirmed by magnetic resonance imaging (MRI) (Westmark et al., 1997; Gurkanlar et al., 2006). Recently, a patient with CDH attending our hospital experienced this exceptional condition after 1.5 months of conservative treatment. In the following report, we will present this case and discuss the condition.

\section{Case}

A 41-year-old woman was admitted to hospital because of neck and left arm pain and numbness at left arm. In addition, there had been no obvious improvement in her condition after taking nonsteroidal drugs.

On physical examination, C7 sensory level hypoesthesia was demonstrated, her motor power was assessed as grade 4 . Although there were no remarkable findings on plain X-ray films, MRI showed a disc herniation at the C6-7 level (Fig. 1a-b). In addition, the MRI showed obvious compression to left $\mathrm{C} 7$ radix. The diagnosis established, we recommended that the patient undergo anterior cervical discectomy and fusion. However, she refused the surgery and discharged herself. At a follow-up examination 1.5 months later she stated that her symptoms had begun to show rapid improvement and she had regained her motor strength and numbness in her left arm had resolved completely. A follow-up MRI 1.5 months later showed complete regression of the herniated cervicaldisc (Fig. 2a-b).

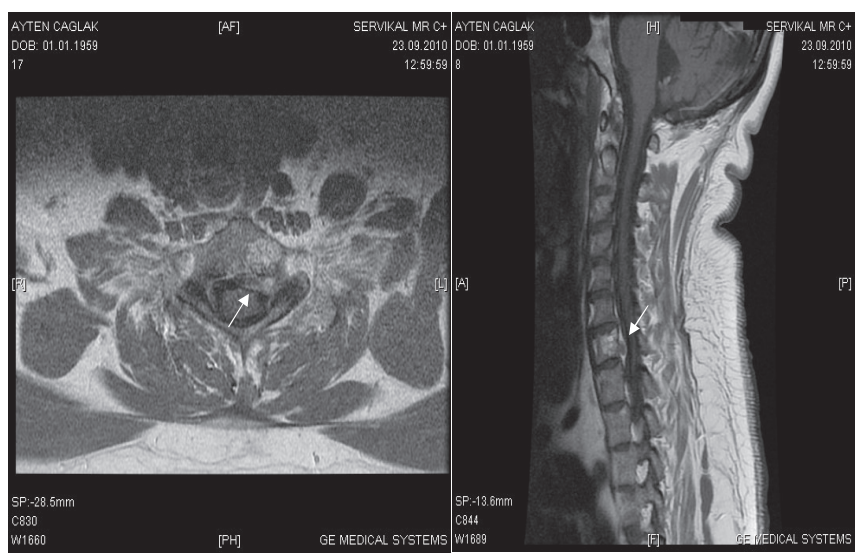

Fig. 1a-b. MRI showing C6-7 cervical disc compresion to left C7 radix. 

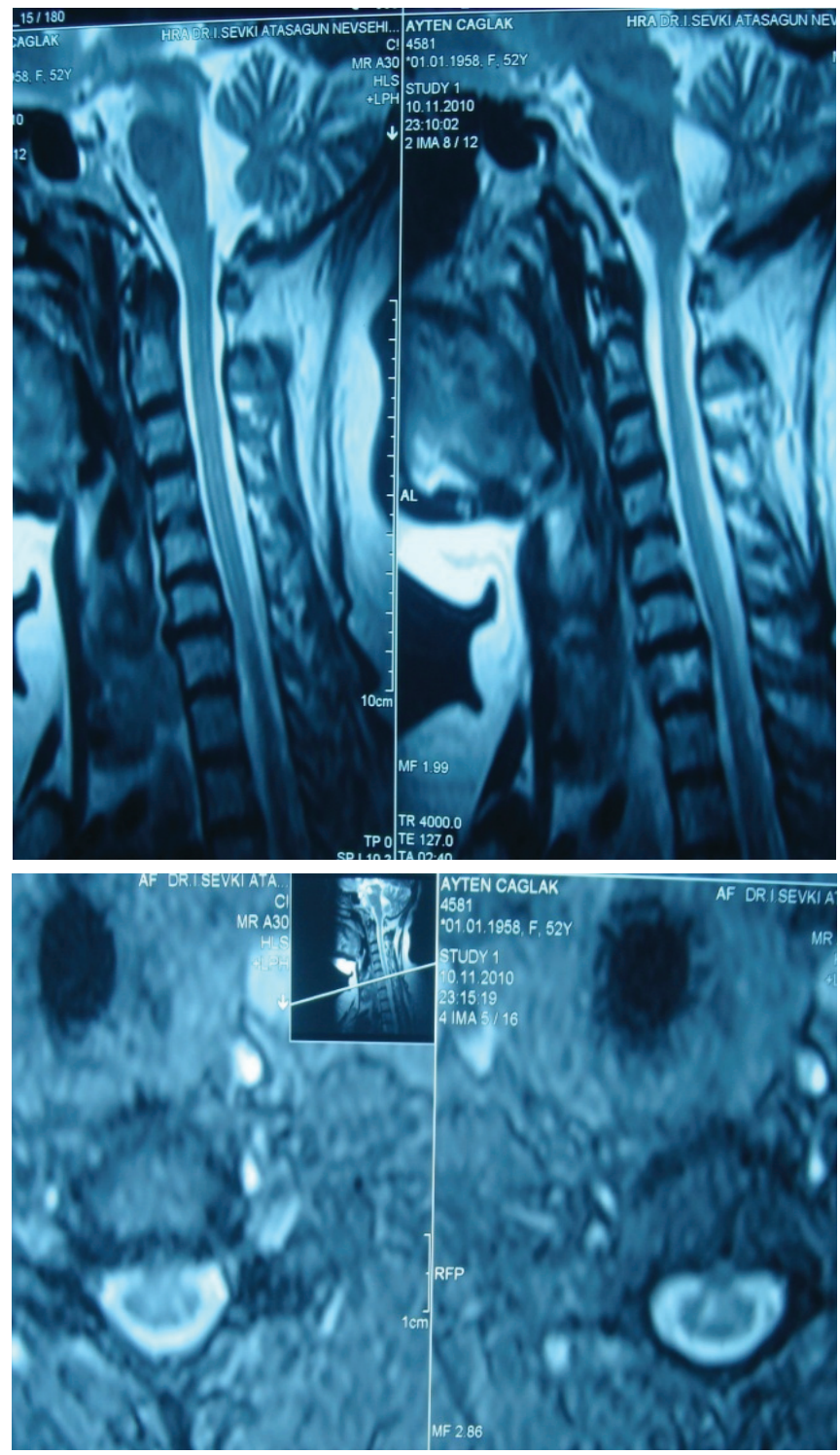

Fig. 2a-b. After 1.5 months of conservative treatment, MRI shows complete regression of the herniated disc.

\section{Discussion}

Since the first report of spontaneous regression of a herniated cervical disc by Krieger and Maniker in 1992 ( Krieger and Maniker, 1992 ), several other authors have also reported this rare phenomenon (Mochida et al., 1998; Gurkanlar et al., 2006). Usually, patients with myelopathy, a condition which is more severe than radiculopathy, are impatient for their neurological deficits to resolve. Therefore, in the absence of knowledge about the natural history of such patients, doctors are apt to choose surgical treatment. Many factors relating to the resorption process have been recognized, including the age of the patients, dehydration of the expanded nucleus pulposus, resorption of hematoma, revascularization, penetration of herniated cervical disc fragments through the posterior longitudinal ligament (PLL), size of disc herniation, and existence of cartilage and annulus fibrosus tissue in the herniated material. Resorption of a herniated nucleus pulposus is thought to occur via an inflammatory reaction in the outermost layer of the herniation, with macrophages as the major cellular population. Komori et al.(Komori et al.,1998; Mirzai et al., 2003) reporting 77 cases of spontaneous resorption lomber disc herniation. In this article, author explain that, when herniated disc material entry to epidural vascular area, neovascularisation and inflammatory process begin and it provides macrophage phagocytosis and resorption.

In previously reported cases, spontaneous regression of a herniated cervical disc has been found more frequently in extruded than in protruded discs (Kobayashi et al., 2003). Larger type herniations are likely to regress more readily than smaller ones because of their tendency to penetrate the annulus fibrosus and PLL, there by being exposed to the systemic circulation in the epidural space. Evidence of regression has been seen more frequently in patients who underwent imaging soon after the onset of symptoms than in those in whom imaging was delayed (Mochida et al., 1998).

Spontaneous regression of herniated cervical disc is rare. As all previously reported cases have been of the extruded type, nonsurgical management may be considered as an option for the treatment of patients with a cervical extruded disc.

In older patients, the immunologic response and angiogenesis needed for CDH resorption may be weaker. Herniations tend to have less nucleus pulposus and more hardened annulus fibrosus and cartilaginous endplate material (Mochida et al., 1998), the latter is able to inhibit neovascularization of the herniated disc (Kokubun et al., 1996). In younger patients, the inflammatory response may be less pronounced.

The patients with cervical disc hernia, if the findings of cervical myelopathy or cervical radiculopathy has identified surgical treatment is usually planning. Because replacement of disc fragments increases the risc of acute cord compresion and radicular pain.

Although the generalization that cervical disc herniations can be successfully managed with nonoperative management would be inappropriate from the results of only a few cases, conservative observation for at least two or three months could be considered as an option for patients with cervical disc herniation, especially those with complicated medical conditions.

\section{REFERENCES}

Guinto, F.C., Hashim, H., Stumer, M., 1984. CT demonstration of disk regression after conservative therapy. AJNR Am. J. Neuroradiol. 5, 632633.

Gurkanlar, D., Yucel, E., Er, U., 2006. Spontaneous regression of cervical disc herniations. Minim. Invasive Neurosurg. 49, 179-183.

Pan, H., Xiao, L.W., Hu, Q.F., 2010. Spontaneous regression of herniated cervical disc fragments and its clinical significance. Orthoped. Surg. 2, 77-79.

Keskil, S., Ayberk, G., Evliyaoglu, C., 2004. Spontaneous resolution of 'protruded' lumbar discs. Minim. Invasive Neurosurg. 47, $226-229$.

Kobayashi, N., Asamoto, S., Doi, H., 2003. Spontaneous regression of herniated cervical disc. Spine J. 3, 171-173.

Kokubun, S., Sakurai, M., Tanaka, Y., 1996. Cartilaginous endplate in cervical disc herniation. Spine. 21, 190-195.

Komori, H., Okawa, A., Haro, H., 1998. Contrast-enhanced magnetic resonance imaging in conservative management of lumbar disc herniation. Spine, 23, 67-73. 
Krieger, A.J., Maniker, A.H., 1992. MRI-documented regression of a herniated cervical nucleus pulposus: a case report. Surg. Neurol. 37, 457459.

Mirzai, H., Umur, A.S., Barutcuoglu, M., Tosun, C., Akbasak, A., 2003. Spontan resolutıon of a herniated cervical disc. T. Klin. J. Med. Sci. 23, 480-482.

Mochida, K., Komori, H., Okawa, A., 1998. Regression of cervical disc herniation observed on magnetic resonance images. Spine. 23, 990995.

Song, J.H., Park, H.K., Shin, K.M., 1999. Spontaneous regression of a herniated cervical disc in a patient with myelopathy. Case report. J. Neurosurg. 90, S138-S140.

Westmark, R.M., Westmark, K.D., Sonntag, V.K., 1997. Disappearing cervical disc. Case report. J. Neurosurg. 86, $289-290$. 